This item was submitted to Loughborough's Research Repository by the author.

Items in Figshare are protected by copyright, with all rights reserved, unless otherwise indicated.

\title{
Design limits of unbonded laminate tooling for pressure die-casting
}

PLEASE CITE THE PUBLISHED VERSION

PUBLISHER

Professional Engineering Publishing / @ IMechE

VERSION

VoR (Version of Record)

LICENCE

CC BY-NC-ND 4.0

REPOSITORY RECORD

Soar, Rupert C., and Phill M. Dickens. 2019. "Design Limits of Unbonded Laminate Tooling for Pressure Diecasting". figshare. https://hdl.handle.net/2134/4717. 
This item was submitted to Loughborough's Institutional Repository (https://dspace.lboro.ac.uk/) by the author and is made available under the following Creative Commons Licence conditions.

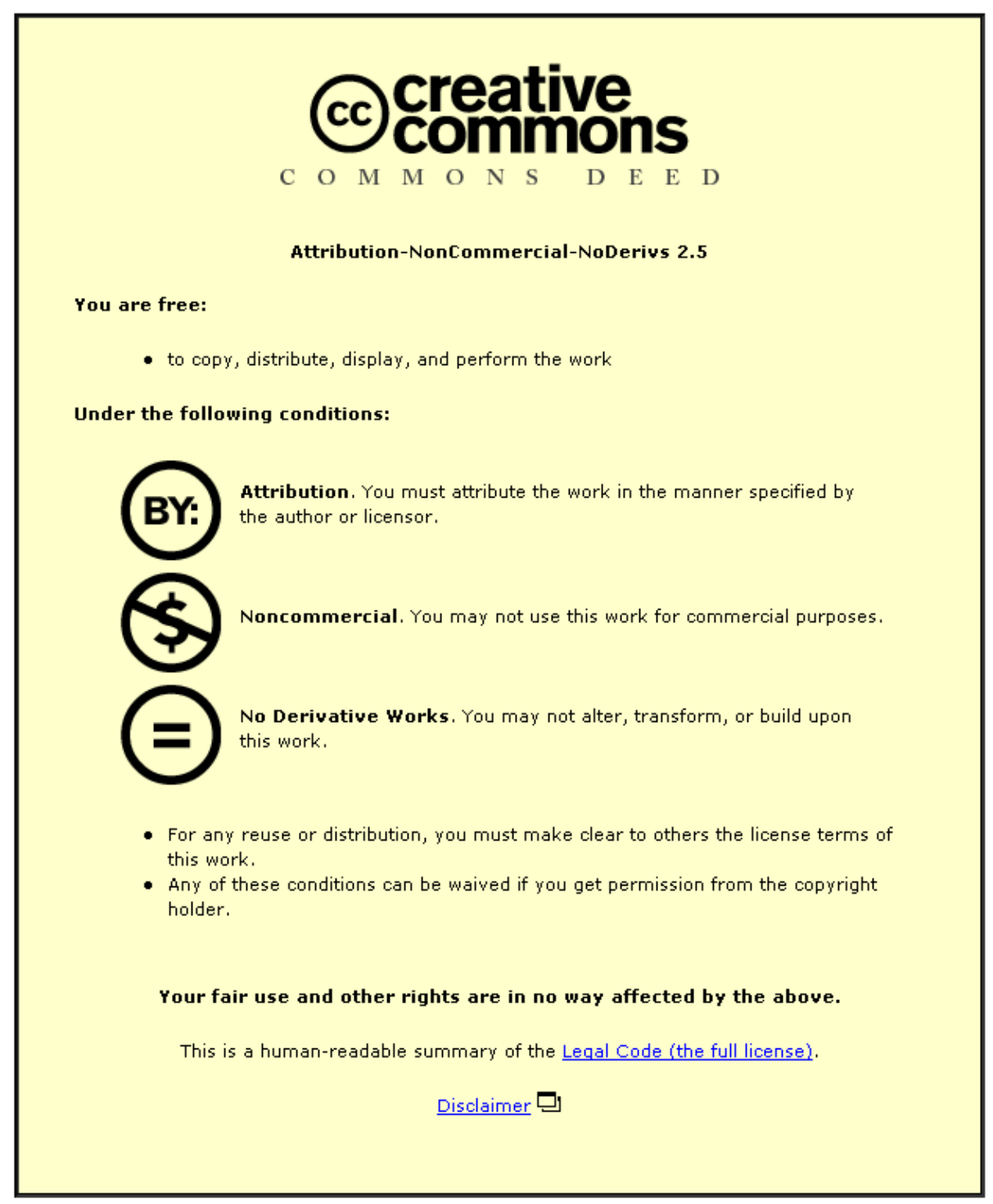

For the full text of this licence, please go to: http://creativecommons.org/licenses/by-nc-nd/2.5/ 


\title{
Design limits of unbonded laminate tooling for pressure die-casting
}

\author{
R Soar* and P Dickens \\ Department of Engineering and Technology, De Montfort University, Leicester, UK
}

\begin{abstract}
This paper describes a new concept for the construction of prototype tooling specifically for pressure die-casting. The tools are made by clamping together laser-cut profiles in $\mathrm{H} 13$ tool steel sheet. The result of this endeavour has been the creation of a low cost, flexible, scalable and robust tooling system for design validation that allows multiple design iterations to be examined on the actual pressure die-casting equipment used in the production environment. Work to date has shown that relatively large up-standing features can withstand the forces of molten metal during injection.
\end{abstract}

Keywords: rapid tooling, laminate tooling, pressure die-casting

\section{AIMS AND OBJECTIVES}

An unbonded laminate high pressure die-casting tool was considered to enhance the flexibility sought in die design validation. Ideally prototype tooling should allow many design iterations to be considered before the final design is set. An unbonded laminate tool would allow the free exchange of individual or sets of laminates to realize this objective. Based on these requirements the following two objectives were formulated:

(a) to identify whether an unbonded laminate tool could be designed, constructed and run on a production high pressure die-casting machine;

(b) if an unbonded laminate pressure die-cast tool could withstand this environment, what would be the design limits for such a tool?

\section{BACKGROUND TO LAMINATE TOOLING}

There were certain fundamental design issues that had to be addressed specific to laminate tooling for pressure diecasting. Laminate tooling is not a new concept; groups around the globe have developed and applied the process to various forming applications that include blanking and deep drawing tools $[\mathbf{1}, \mathbf{2}]$, sheet forming tools [3-5], foam moulding and thermoforming tools $[\mathbf{6}, 7]$, finishing tools [8] and injection moulding tools [9-12]. Of these groups

The MS was received on 11 May 2000 and was accepted after revision for publication on 15 August 2000.

*Corresponding author: Department of Engineering and Technology, De Montfort University, The Gateway, Leicester LE1 9BH, UK.
Dickens et al. cite a laminate thermoform tool still in full-scale production over the last five years at Ford, USA, and Nakagawa [13] cites a technique for laminate blanking tools in use by Hanai Engineering, Japan, with the production of over 10000 tools.

On the basis of the authors' experience in the field of laminate tooling various benefits have come to light that this process offers over conventional tooling processes.

1. Laminate tooling is scalable. Tool size is only limited by the maximum sheet size which can fit on a profiling bed.

2. It is possible to go from computer aided design (CAD) to assembled tool in a matter of days.

3. Laminate tooling allows for the inclusion of deep narrow features within a tool that a milling cutter cannot reach into.

4. For volumes over $500 \mathrm{~mm} \times 500 \mathrm{~mm} \times 500 \mathrm{~mm}$, sheet steel is less expensive than billet.

5. There is often a shorter lead time for the production of the same volume of sheet steel as for billet, as it can be purchased 'off the shelf'.

6. Modern rolling techniques can impart a finer grain structure to the sheet than is possible from cast and forged billet.

7. Complex internal features can be modelled and produced in the tool such as conformal cooling channels.

8. The range and variety of sheet material are much greater; this may involve a different thickness of sheet in the same tool or different sheet material in the same tool.

9. The concept of low cost tooling allows manufacturers to consider short production runs to maintain a competitive edge. 
10. Sections and internal features within a laminate tool can be replaced or modified through the exchange of laminates.

Laminate tooling is, essentially, a low cost, robust and, most importantly, very scalable and flexible rapid tooling concept. The concept has been successfully applied to various tooling applications over the last 20 years, but has not yet generally competed with other emerging rapid tooling concepts to find commercial acceptance, such as laser sintered/fused metal powders (Eosint's DMLS, DTM's RapidTool and 3D's Keltool processes).

One emerging field that laminate tooling could satisfy is the growing need for die design validation based on the high costs involved in correcting poorly designed dies in the pressure die-casting industry. Within this field, there are currently no rapid tooling processes that fully address the need for large-scale $(>500 \mathrm{~mm} \times 500 \mathrm{~mm} \times 500 \mathrm{~mm})$, low cost $(<£ 10000$ per tool), robust (operating at $>200 \mathrm{MPa}$ and $750^{\circ} \mathrm{C}$ ) tooling specifically for die design validation or even short-run tooling.

\section{LAMINATE TOOLING FOR DIE DESIGN VALIDATION}

When laminate tooling is being considered for die design validation one further point must be addressed. For applications such as blanking, deep drawing and injection moulding much of the work carried out to date has concerned itself with the bonding of the laminates that make up the tools. This has been driven by the assumption that the laminates that make up a tool will deflect, which could lead to permanent damage of the internal features. Bonding laminates in a tool is problematic. Various techniques have been applied such as diffusion bonding, solid phase welding and hot forging and all attempt to constrain the laminates so that the tool behaves as if machined from solid billet. For die design validation this presents a problem.

Specifically, to retain the flexibility that laminate tooling could offer the designer through the appraisal and validation of multiple design iterations before the design 'freeze', the tool would have to be constructed without the laminates that make up the tool being bonded. If an unbonded laminate tool could withstand the die-casting process then the following benefits could be realized by the die designer:

(a) appraisal of the design under production conditions;

(b) assessment of heat transfer and shrinkage during cooling;

(c) most effective layout of cooling channels;

(d) effective gate and runner design;

(e) exchanging laminates to introduce new features to the die;

(f) exchanging laminates to change orientation of internal detail of the die; (g) multiple iterations before the final 'design freeze';

(h) faithful reproduction of die-cast parts for fit, form and function testing;

(i) effectiveness of the ejection system in the production tool;

(j) potential for using the tool for short production runs.

\section{THE DIE-CASTING PROCESS}

If laminate tooling is to be applicable to die design validation then it must be applicable to all pressure diecasting processes. This immediately sets the constraint that a laminate prototype tool must withstand the diecasting process with the highest pressures, temperatures and production rates. The one process that stands out is horizontal, cold chamber, high pressure die-casting. This process is the most widely used in the die-casting industry and was developed primarily for the die-casting of aluminium alloys. For the experiments done at De Montfort University a horizontal 'cold chamber' $125 \mathrm{t}$ DAK Frech die-casting machine was used.

\section{SHEET MATERIAL}

One of the most difficult issues was the selection of the sheet steel that would be used to construct the die. Many issues were encountered and included:

(a) the thickness of the sheet required;

(b) the grade of steel used;

(c) flatness in the sheet material.

As with all rapid prototyping and tooling processes there is a trade-off between the thickness of the layers used to construct the part or tool and the time taken. Laminate tooling is no different, in that a tool can be constructed very quickly if very thick sheets of steel are used. However, this will result in a high degree of 'stepping' on the surface of the tool. Likewise, a high level of detail can be achieved if very thin sheet steel is used, but, conversely, it would take a long time to construct such a tool. In addition, if the sheets are too thin then they will not withstand the forces at work in the die-casting process and will permanently deform.

Previous work had shown that the sheet thickness that gives the maximum detail for the minimum number of sheets in a laminate tool lies between 0.5 and $2 \mathrm{~mm}$. For pressure die-casting, high carbon strip steels and low alloy plate are not suitable owing to the temperatures present in the process (LM24 has a melting point of $690-700^{\circ} \mathrm{C}$ ). In addition, thermal fatigue (heat checking) is an important issue in die-casting owing to the rapid heating and cooling of the die during the casting cycle and this limits the type of steel alloy that can be used. The most frequently used steel for pressure die construction is H13 'hot work' tool steel. 
CS Engineering, Japan, supplied a $\frac{1}{2} \mathrm{t}$ consignment of cold-rolled $\mathrm{H} 13$, at $1 \mathrm{~mm}$ thickness. They could not achieve any thickness less than $1 \mathrm{~mm}$, and this, automatically, set the minimum sheet thickness that would be used.

Cold rolling imparts a very clean finish to the steel and the process enhances the grain structure of the sheet further. However, it also sets up stresses in the sheet that may distort the sheet during laser cutting and hardening/tempering required later. The cold-rolled sheet had a mean thickness of $1.045 \mathrm{~mm}$ (range of $0.06 \mathrm{~mm}$ ).

\section{LAMINATE ORIENTATION}

Laminate orientation relates to the direction that the laminates are stacked with respect to the parting line of the tool. The two most commonly used approaches are either vertical (laminates are oriented perpendicular to the parting line) or horizontal (laminates are oriented parallel to the parting line). Previous laminate tools, such as the blanking and deep drawing tools built by Nakagawa [13], have tended towards horizontal stacking owing to the large compressive loads on the tool in one direction. This approach presents a problem when applied to die construction where up-stand detail exists and can lead to 'islands' of laminates. These 'islands' would require a separate clamping arrangement for each up-stand that, in a complex die-cast tool, would be impossible to accommodate. The optimum solution, in die-casting, is to arrange the laminates vertically as shown in Fig. 1.

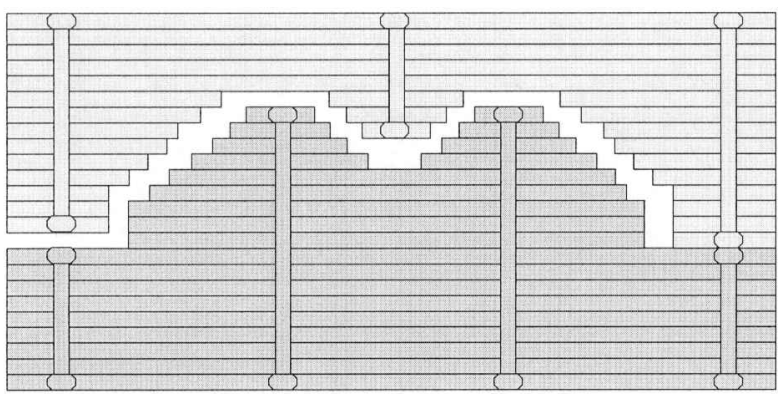

Example of Horizontal Laminate 'Islands'

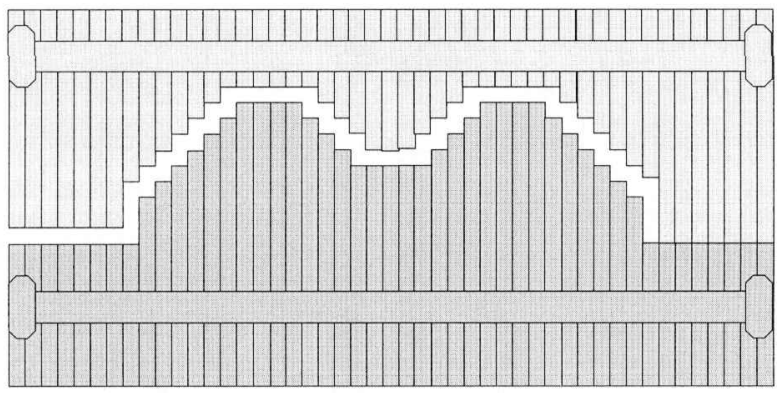

Example of Vertical Laminate Clamping

Fig. 1 Considerations with horizontal or vertical laminate orientation
In this arrangement all the relevant detail can be incorporated in the die with all the laminates constrained by a single clamping procedure for each half of the die. Vertical alignment does present its own problems, in an unbonded laminate die, in that those laminates that form an up-stand feature may be exposed to excessive deflection caused through the action of the molten alloy entering the die cavity.

\section{EXPERIMENTAL DESIGN}

A test die was designed with an array of up-stand features arranged so that each one presented a single laminate protrusion on which the force of the incoming molten alloy would act. The features were designed to represent the 'worst-case scenario' that an unbonded laminate die would experience in the production environment. The features would form a $45^{\circ}$ ramp made up of vertically oriented laminates, at the back of which the last laminate would protrude in $1 \mathrm{~mm}$ increments as shown in Fig. 2.

A total of eight ramp features were used in the test die in different positions in the cavity. For each run of castings the height of the laminate protrusions would be increased in $1 \mathrm{~mm}$ increments from $1 \mathrm{~mm}$ protrusion (A) to $6 \mathrm{~mm}$ (B) in Fig. 2. A situation where a laminate protrudes by as much as $6 \mathrm{~mm}$ on a feature that is $10 \mathrm{~mm}$ high (the laminates protrude $16 \mathrm{~mm}$ above the main body of the laminate stack) was considered to be extreme and therefore defined the height limit. It was expected that if the magnitude of deflection on any one laminate exceed a certain amount then a gap between the laminate protrusion and the ramp feature would appear and molten alloy would be forced down it. If this occurred in any of the laminate protrusions on a run then the die would have been deemed to have failed at that height.

One further reason for the selection of eight ramp features, within the die, was to overcome the effects of a feature's location with respect to the inlet gate. In all die-cast dies there is a significant change in the force the molten alloy can exert on the internal features as it progresses through the die. The change in force is dependent on:

(a) the distance of a feature from the inlet gate;

(b) the temperature drop across the die;

(c) the fluidity/viscosity of the molten alloy;

(d) the design of the inlet gate;

(e) the shape of the die cavity;

(f) the shape of the feature.

Having only one laminate protrusion would give no indication of problems in the rest of the die cavity. In line with this, if just one of the eight laminate protrusions showed any sign of ingress during a run then the die would have been deemed to have failed at that height. Ingress of molten aluminium alloy would appear on a 

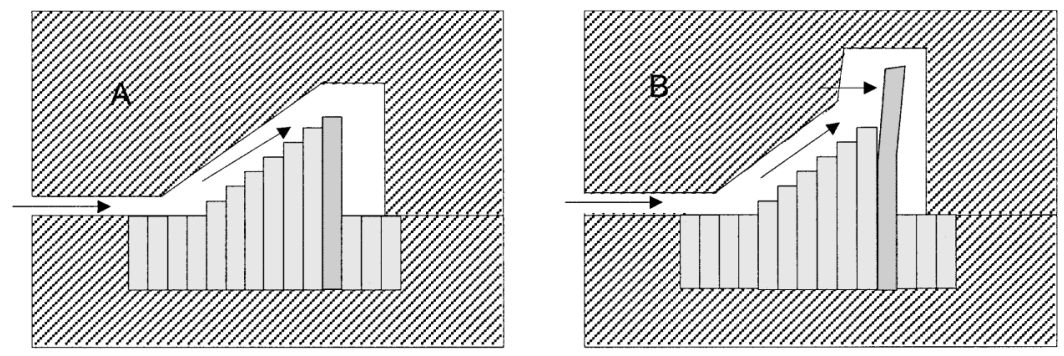

No Laminate Protrusion

Laminate Protrusion

Pronounced

Witness Mark

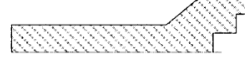

Fig. 2 The laminate ramp feature and visible witness mark on casting

casting as a visible witness mark once the casting was sectioned, also shown in Fig. 2.

\section{CONSTRUCTION OF AN UNBONDED LAMINATE PRESSURE DIE-CAST DIE}

The CAD model of the test part is shown in Fig. 3. From this model the upper and lower surfaces were defined from which the two halves of the laminate tool were modelled. The mean thickness of the sheet material was calculated before slicing took place. In addition, a diagonal indexing groove was generated on one face of each tool model so that, once cut, the laminates could be assembled in order prior to being constrained.
When the tool models had been sliced, the individual laminate profiles were exported (via . dxf in this case) to a suitable profiling machine. A $1.5 \mathrm{~kW} \mathrm{CO}$ laser profiler was used. The laminate profiles were 'nested' on to four sheets of the H13 sheet steel (each sheet was $1000 \mathrm{~mm} \times 500 \mathrm{~mm})$.

\section{CONSTRAINING THE LAMINATES}

Constraining the laminates, while maintaining the flexibility to exchange any of them, was a challenge. To constrain the laminates effectively so they could not move while the tool was being used raised the following issues:

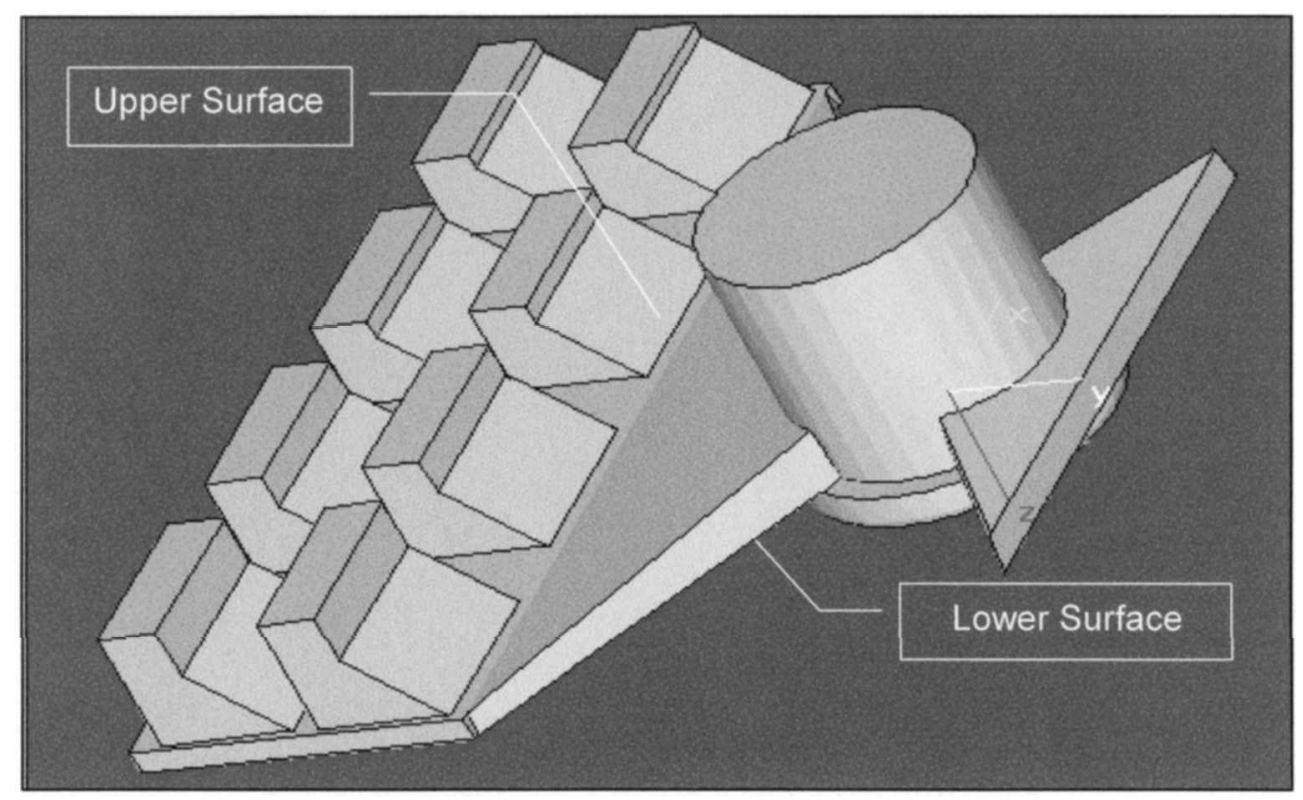

Fig. 3 CAD model of the pressure die-cast component 
1. Compression had to be equal and spread over as large an area as possible.

2. Compression had to be the same however many laminates were replaced.

3. The method of compression had to be simple and not interfere with the effectiveness of the tool design.

For the laminate pressure die-cast tool the laminate sections containing the internal features were created as inserts for a larger solid steel bolster. The bolster was required to support the sprues and bushes and to ensure that the two halves of the die would mate accurately during casting.

Instead of studs running through the laminates the inserts were constrained using wedges. When loosened, a laminate could be replaced more easily, allowing features to be changed between runs.

The inserts had two solid, $15 \mathrm{~mm}$ thick, H13 endplates to spread the compressive loads evenly over the width of the laminate stack and a solid H13 central section. The solid central section was used as a precautionary measure as this was the part of the tool that the molten alloy impinged on before being deflected $90^{\circ}$ through the inlet gate. The sliding wedge acted between the end-plate and the side of the bolster and is ringed in Fig. 4.

The final issue to resolve was to ensure that, when laminates were replaced and compressed with the wedges, the geometric tolerances were maintained on the internal features of the die. Compression had to be constant between exchanges as this affected the amount of movement in the individual laminates in the tool. As laminates were exchanged in a tool the slight difference in thickness affected the length of the tool. In practice, however, a laminate prototype tool does not require the tolerances expected in a production tool (typically $\pm 0.05 \mathrm{~mm}$ ) as it is used only for design validation.

With prototype tooling, where the exchange of laminates is important, the assumption is made that some laminates will be more and some less than the mean thickness of the steel sheet and these will average out. When compressing the laminates, after an exchange, the objective is to compress the laminates so that the through-holes for the ejector pins line up with the through-holes in the bolster, allowing the ejector pins to pass through to the ejector plate.

\section{FINISHING THE LAMINATE TOOL}

The final details the tool required were:

(a) ejector pins and inlet gate;

(b) the parting line/plane;

(c) hardening and tempering.

When forming the through holes for the ejector pins and the inlet gate, it is unwise to drill or mill the laminates. The act of drilling between laminates can easily snap a drill bit if the tip should become lodged between two laminates. With laminate tooling the safest option is to use electrodischarge machining. When the two halves of the tool were assembled, shown in Fig. 5, a clean parting plane was ground onto both halves of the tool to prevent flashing during casting.

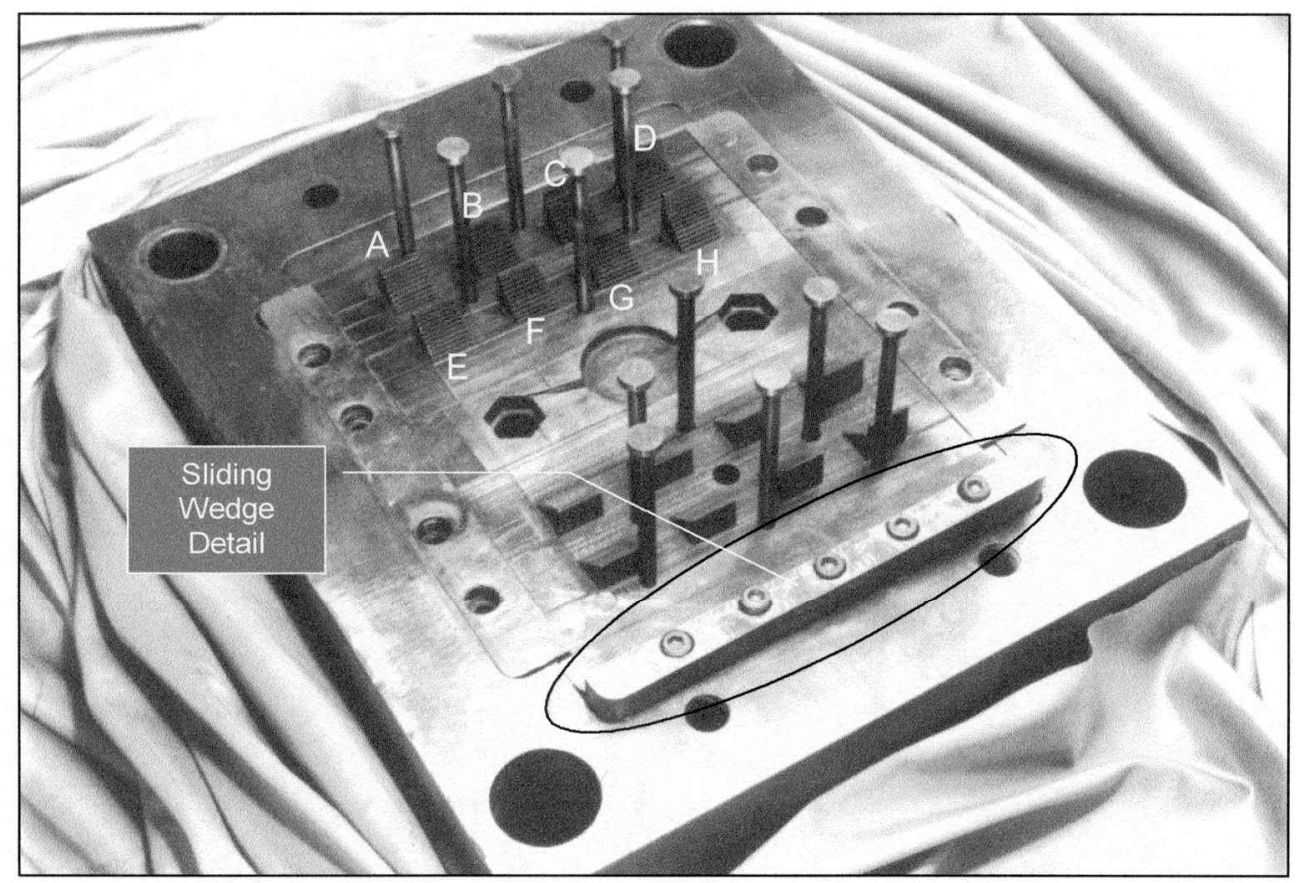

Fig. 4 Sliding wedge on male (ejector) half of die-cast tool 


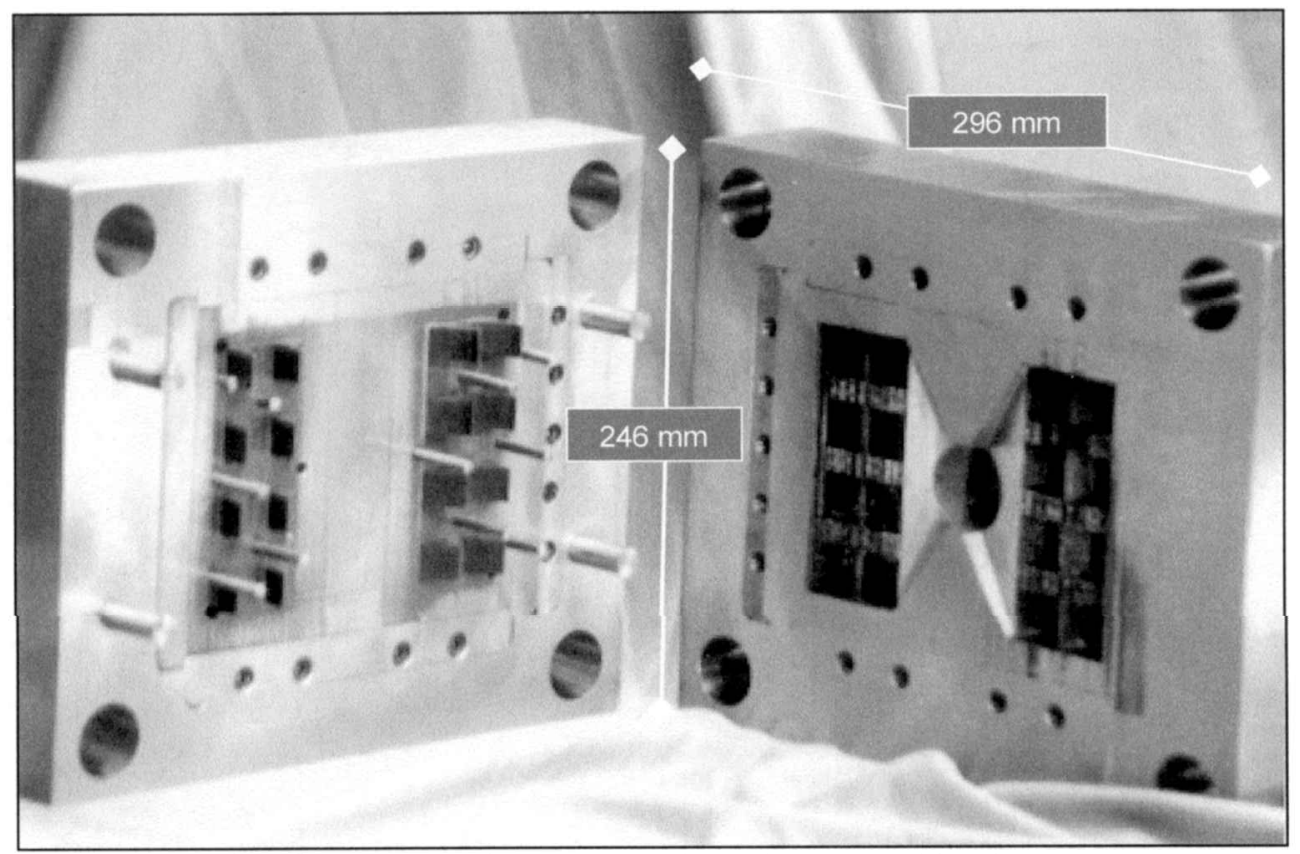

Fig. 5 Completed laminate tool

When the tool was first assembled and the parting plane ground, there was a close fit between the two halves of the die. Problems can arise when laminates are exchanged and the tool is re-assembled. Continually grinding the parting plane is not an option, as this will affect the thickness of the castings. The key to exchanging laminates is to ensure that any new laminates inserted into the laminate stack do not stand proud of the parting plane.

The H13 laminate profiles used in the demonstration tool arrived in the annealed condition (24 HRC) and had to be hardened/tempered to around 48-50 HRC as the hardness of the laminates relates to their ability to resist deflection forces during the casting cycle. Various approaches were tested to achieve the desired hardness in the laminates, but only one process proved consistent. This was vacuum heat treatment with a nitrogen quench.

If the individual laminate profiles are heat treated before the tool is assembled, then distortion occurs owing to the stress relief. In addition, if conventional hardening processes are used on individual laminates, prior to assembly, then a migration of the carbon $(0.39$ per cent) in the tool steel occurs that reduces hardness.

This is a specific problem where thin laminates are allowed to react with the atmosphere during heat treatment. Therefore, the laminates that make up a pressure die-cast tool should be first assembled and then constrained before hardening/tempering in a vacuum furnace and nitrogen quench. Distortion still occurs during heating but is minimized by constraining the laminates first.

\section{EXPERIMENTAL PROCEDURE}

A total of six runs each consisting of 10 complete castings were conducted. Castings were produced prior to each test run to get the die up to casting temperature. The casting alloy was the standard aluminium alloy LM24 (Al-Si8-Cu3; BS 1490, ASTM A380) with a casting temperature of $690^{\circ} \mathrm{C}$. Die temperature pre-heat was $175-200{ }^{\circ} \mathrm{C}$ and the release agent was a Klubertec polysiloxane water-based emulsion.

After each run, with the laminates all set at the same protrusion height, a new laminate was used with the incremental height increases of $1-6 \mathrm{~mm}$ as discussed previously. The castings were sectioned at the end of each run and any visible witness marks on the casting recorded as an indication that a laminate had failed at that particular protrusion height.

One point to note, indicated on the plotted graphs (Figs 7, 10, 11, 12, 13, 14 and 15), is a horizontal line marked MIP. This is a known 'minimum ingress point' or the amount of gap necessary between two laminates before ingress occurs. Previous tests have shown that for LM24 a gap of exactly $0.04 \mathrm{~mm}$ must open up between two laminates before pressurized alloy will flow down it. This statement is borne out by the common practice of including die vents no greater than $0.025 \mathrm{~mm}$ wide that allow the escape of trapped air in the die but not the molten alloy. The line denoting the MIP, therefore, crosses the $y$ axis at $0.04 \mathrm{~mm}$. Any witness marks recorded above this width were definitely ingress, any marks below this width were for other reasons, as will be shown. 


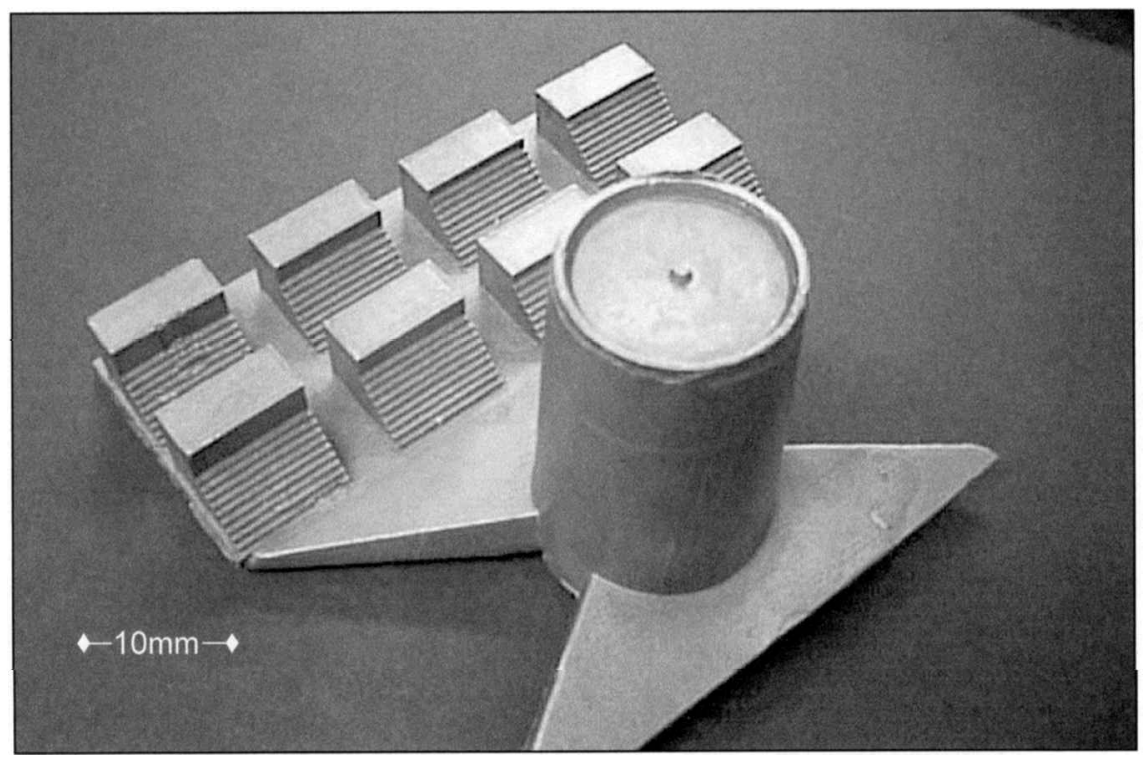

Fig. 6 Casting from laminate test die

\section{RESULTS}

The first run of 10 castings had all the laminates set to $1 \mathrm{~mm}$ above each of the eight ramp features in the test die. One of the first castings is shown in Fig. 6. These castings were sectioned and any witness marks measured with a $(15 \times)$ vernier microscope. The data were plotted and are reproduced in Fig. 7.
It can be seen that no witness marks were measured above the $0.04 \mathrm{~mm}$ MIP, indicating that at $1 \mathrm{~mm}$ no laminates failed in an unbonded laminate tool. There are, however, five measurements below $0.04 \mathrm{~mm}$. These were examined to confirm that they were, in fact, deformation burrs caused through the ejection of the casting off the laminate protrusion features that the casting shrinks to. This can be seen in the scanning electron

\section{Ingress Measurements with $1 \mathrm{~mm}$ Laminate Protrusion}

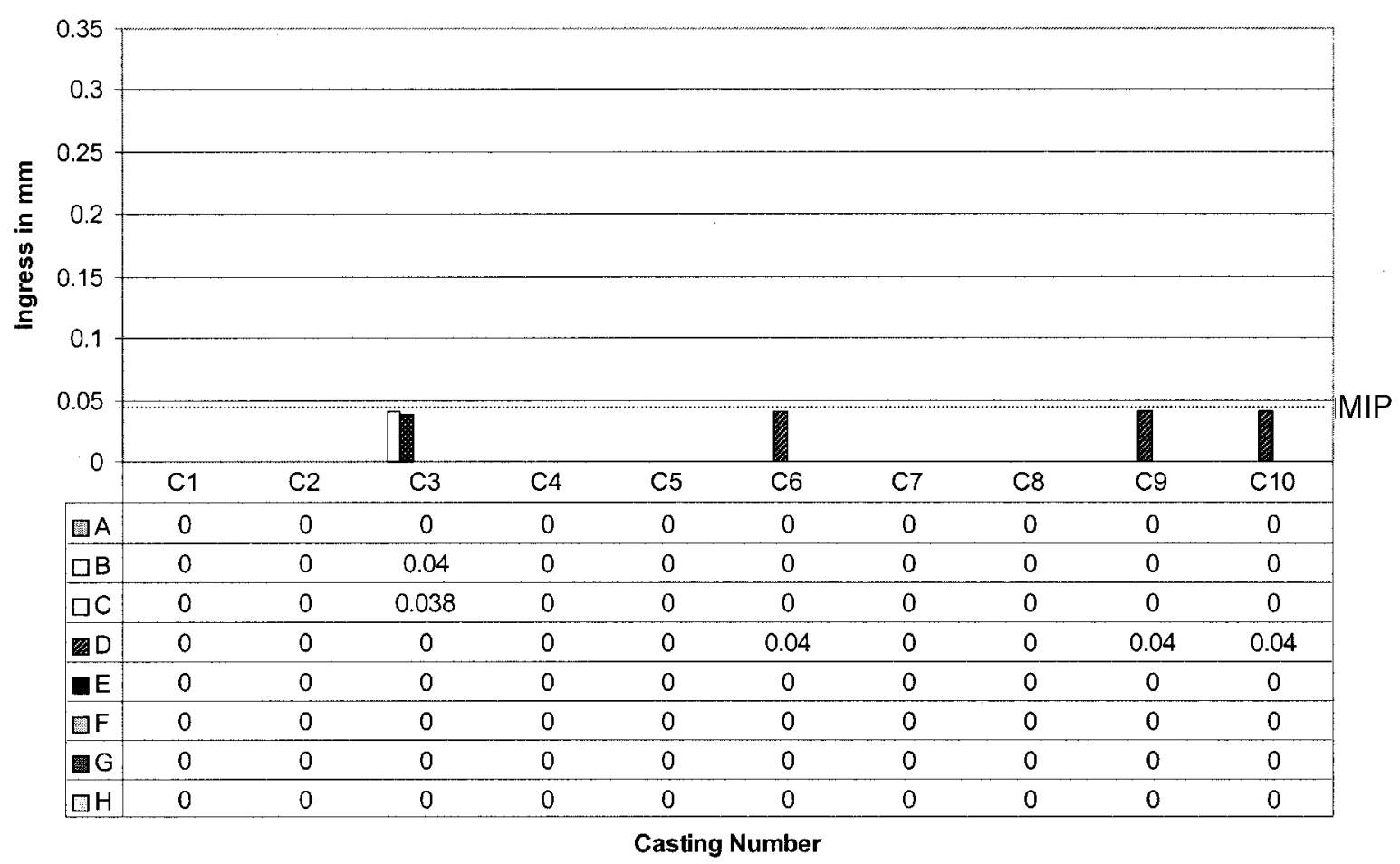

Fig. 7 Plotted data from the $1 \mathrm{~mm}$ run 


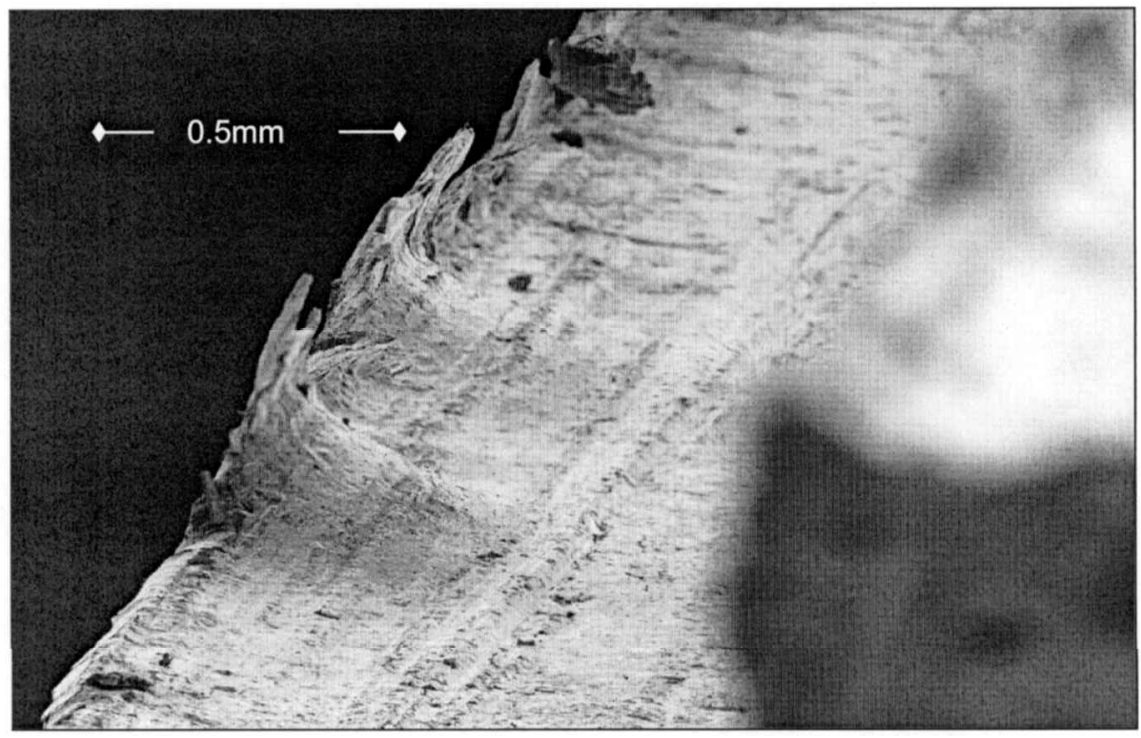

Fig. 8 Deformation burr at $0.04 \mathrm{~mm}$

microscopy (SEM) frame shown in Fig. 8. This is compared with actual ingress, which appears as a distinctive rounded, smooth shape as shown in Fig. 9. The runs conducted with 2, 3 and $4 \mathrm{~mm}$ protrusions are shown in Figs 10, 11 and 12. No ingress was recorded for the 2 and $3 \mathrm{~mm}$ runs although the incidence of deformation burrs increased as would be expected as the height of the laminate protrusions increased. Taller laminates required the casting to be withdrawn further to release it from the features it had shrunk onto, creating greater deformation.

The $4 \mathrm{~mm}$ run showed no incidence of ingress until the last two castings in the run of 10 taken from the test die. This appeared to indicate that this was the height at which the laminates in the unbonded die had failed.
This was unusual as if there was sufficient deflection to cause the laminates to deform permanently at this height then ingress might also have appeared at the beginning of the run.

To validate whether $4 \mathrm{~mm}$ was indeed the design limit for an unbonded laminate pressure die-cast die the runs were continued for the 5 and $6 \mathrm{~mm}$ protrusion heights as shown in Figs 13 and 14. From the data it can be seen that there is a large incidence of deformation burrs at these heights but no ingress. A subsequent review of the notes taken during the $4 \mathrm{~mm}$ run revealed that a casting had partially seized on the seventh casting (C7) in the run and its removal had damaged the laminates in that part of the test die.

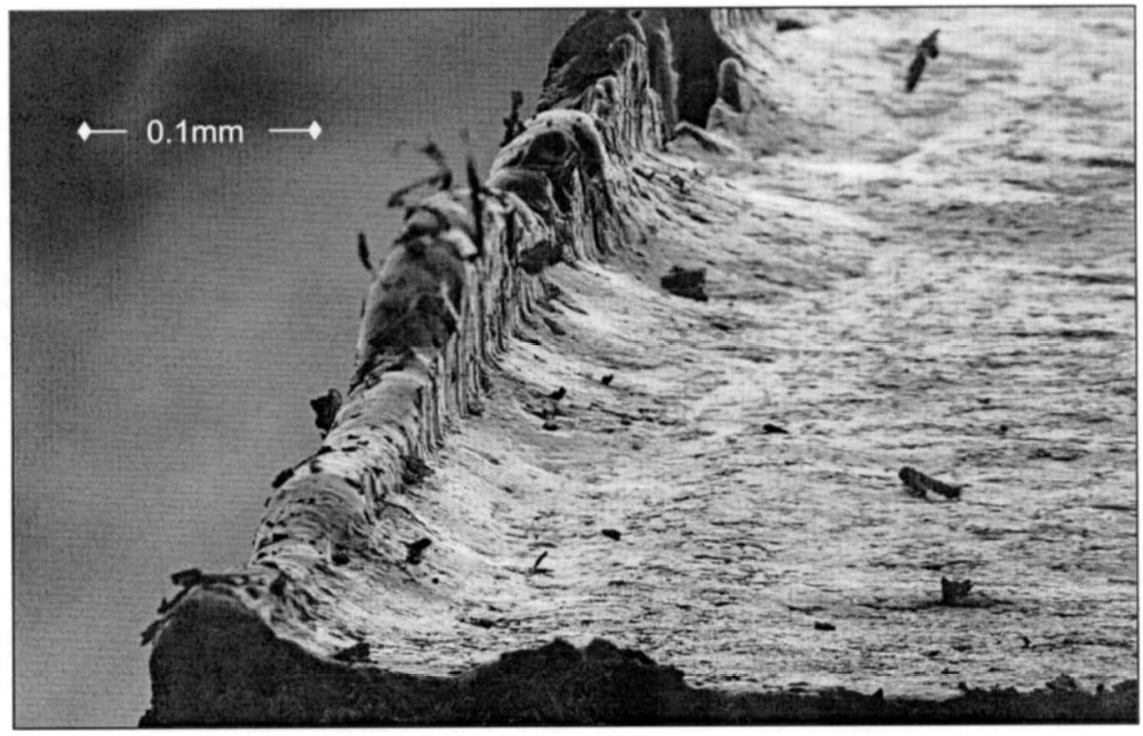

Fig. 9 Smooth rounded appearance of ingress at $0.05 \mathrm{~mm}$ 
Ingress Measurements from 2mm Run

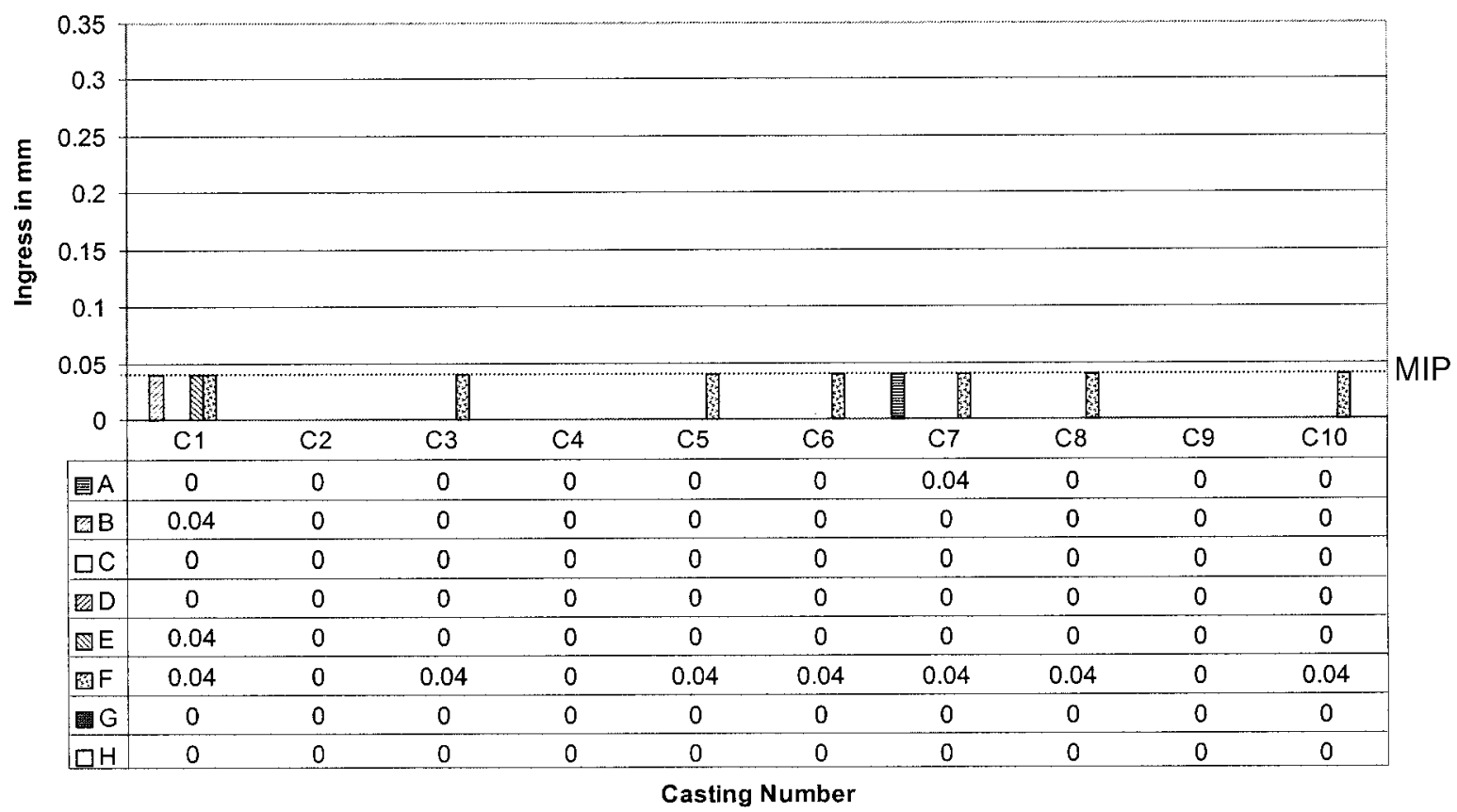

Fig. 10 Plotted data from the $2 \mathrm{~mm}$ run

\section{DISCUSSION}

On the basis of the limitations of the die construction the maximum height that an individual laminate protrusion could be set above each ramp feature was $6 \mathrm{~mm}$. This protrusion height was deemed initially to be far in excess of the height at which ingress between the laminates would be observed. The fact that at $6 \mathrm{~mm}$ the laminates were able to resist the ingress of molten aluminium alloy, and permanent deformation, was unfortunate as it was impossible to establish the maximum height that a laminate would have to extend

Ingress Measurements with $3 \mathrm{~mm}$ Laminate Protrusions

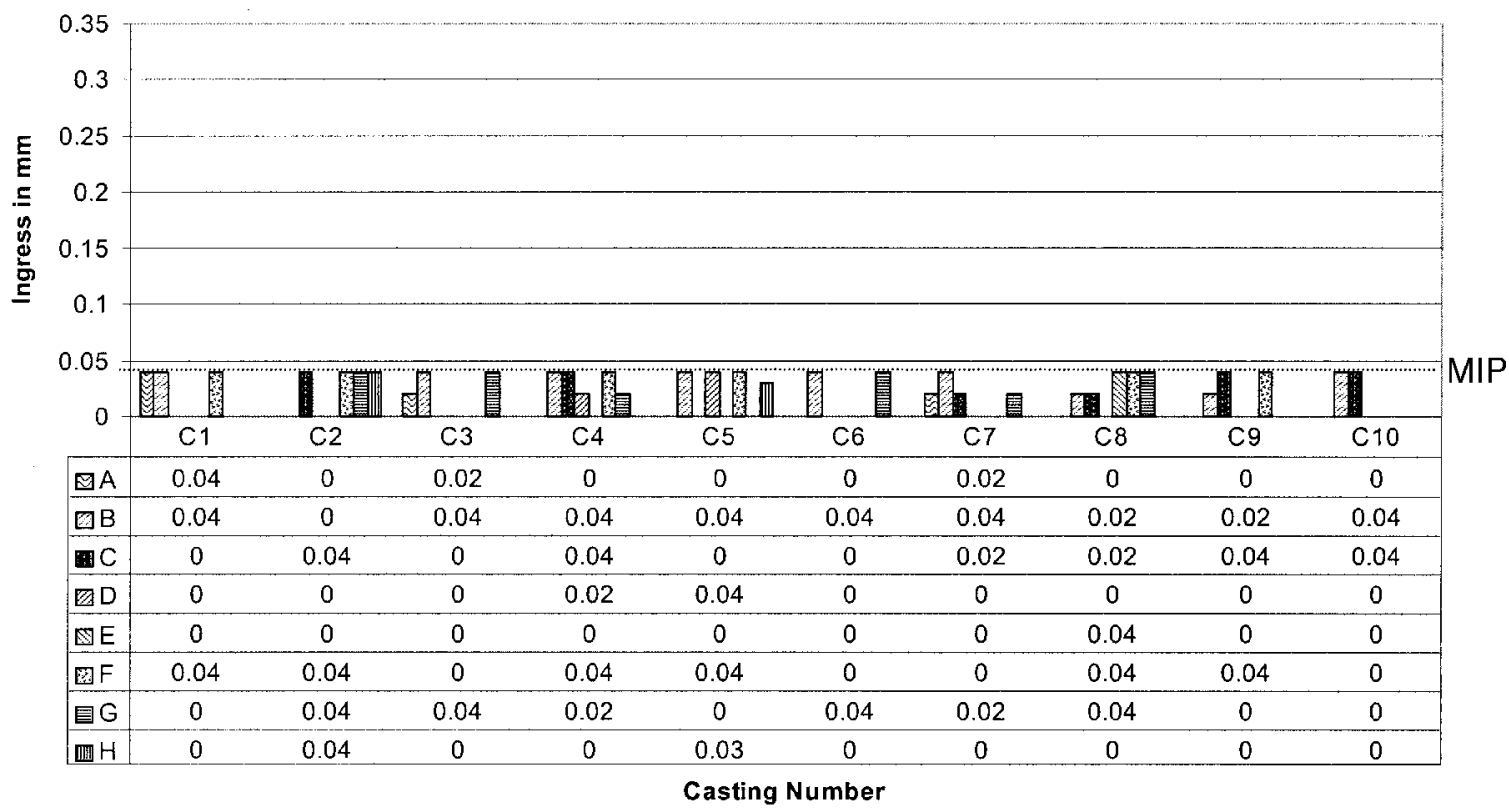

Fig. 11 Data from the $3 \mathrm{~mm}$ run 
Ingress Measurements with $4 \mathrm{~mm}$ Laminate Protrusions

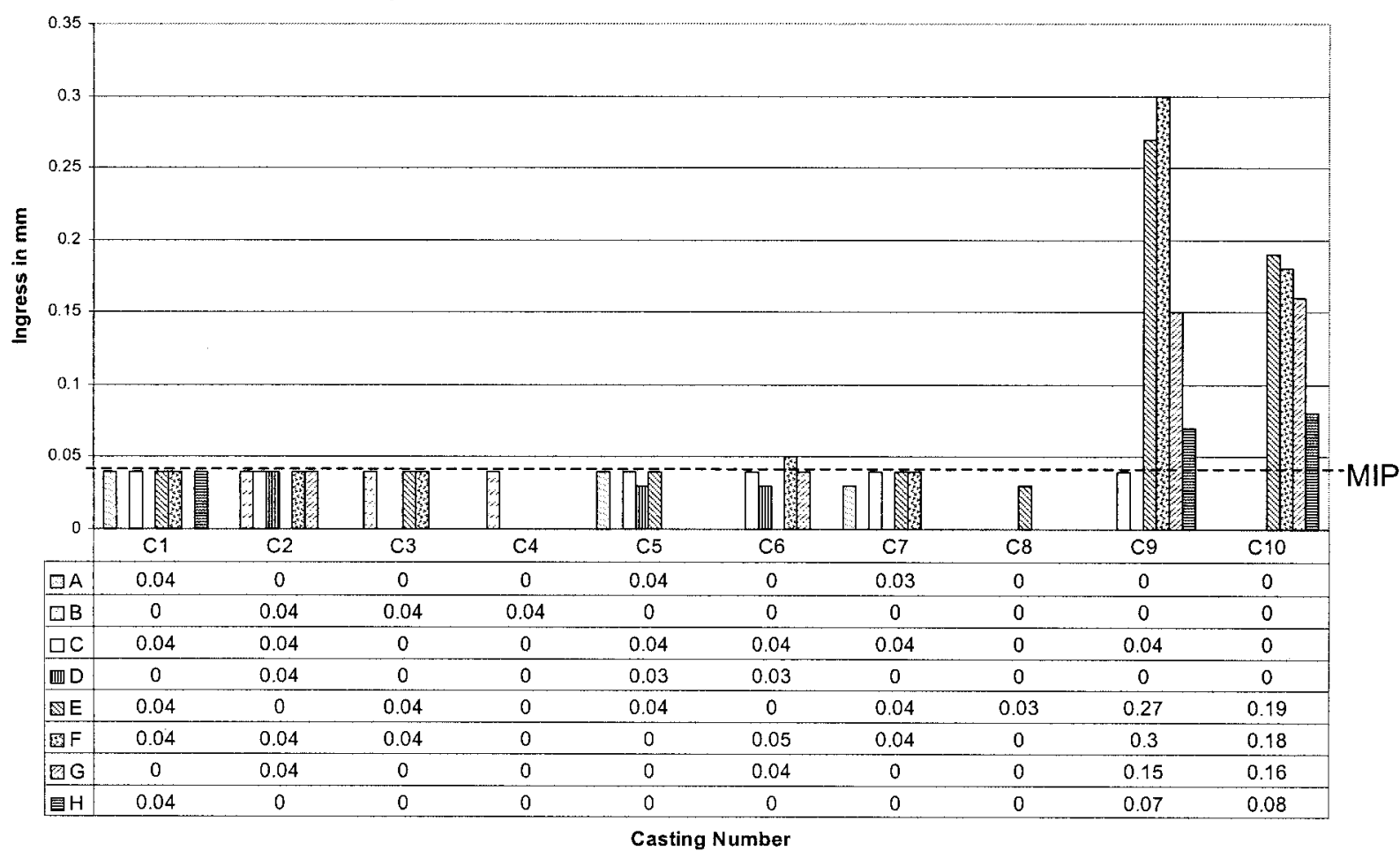

Fig. 12 Data from the $4 \mathrm{~mm}$ run

within any die design before ingress would lead to failure. To establish this limit would have required the complete redesign and construction of a new die set and this fell outside the timeframe.
What was possible, although the data would not be comparable with any previous runs, was to change the variables within the experiment, specifically to increase the injection velocity of the molten alloy entering the

Ingress Measurements with $5 \mathrm{~mm}$ Laminate Protrusions

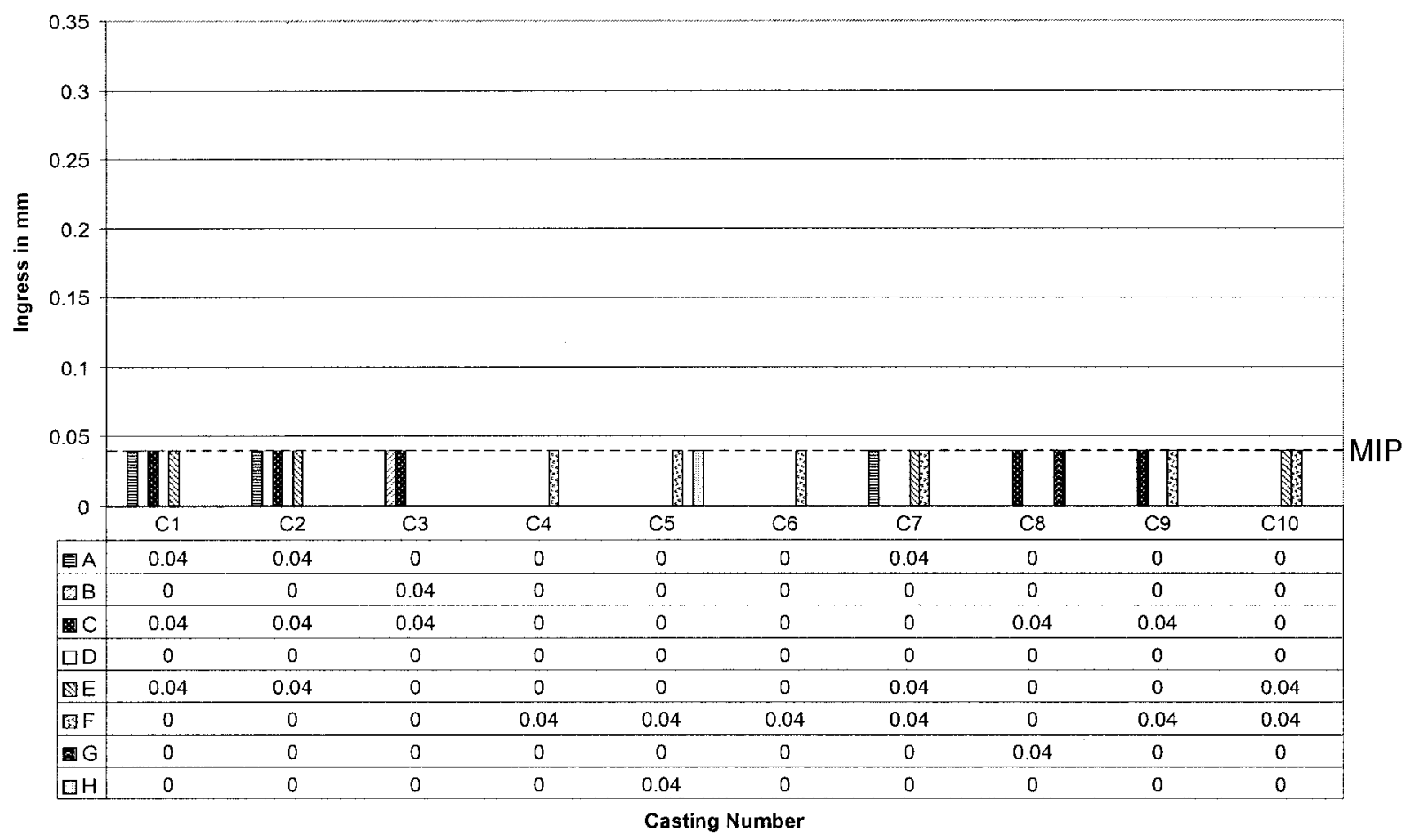

Fig. 13 Plotted data from the $5 \mathrm{~mm}$ run 
Ingress Measurements with $6 \mathrm{~mm}$ Laminate Protrusions

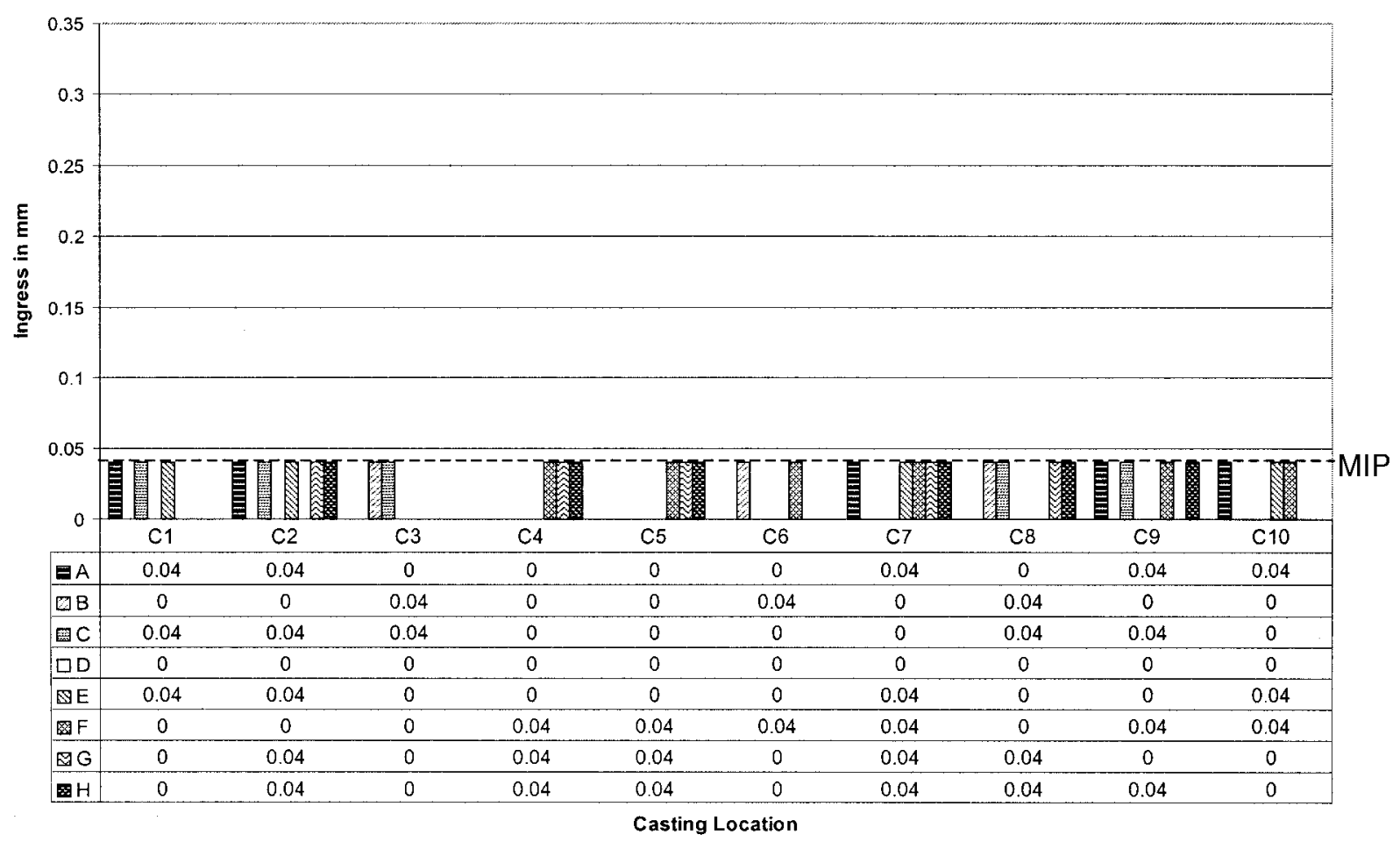

Fig. 14 Plotted data from the $6 \mathrm{~mm}$ run

Repeated 6mm Experiment at 20m/s

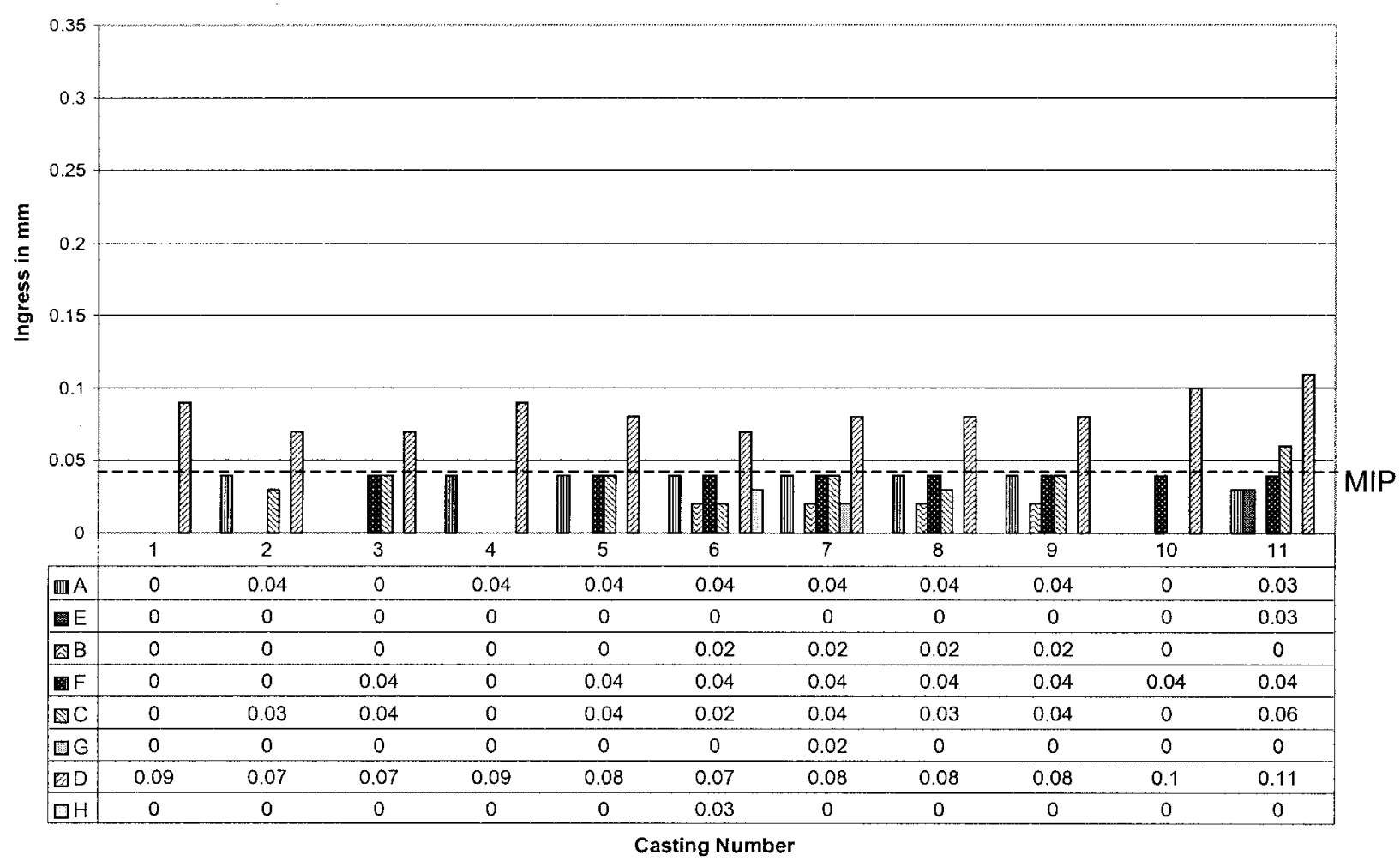

Fig. 15 Plotted data from the repeated $6 \mathrm{~mm}$ run at $20 \mathrm{~m} / \mathrm{s}$ injection velocity 
die cavity. For this set of experiments the injection velocity, during second-phase injection, had been set at $2 \mathrm{~m} / \mathrm{s}$ to prevent spraying of the molten alloy into the die cavity as the alloy passed through the inlet gate. This is by no means the fastest injection speed used within the pressure die-casting industry where figures up to and over $20 \mathrm{~m} / \mathrm{s}$ are used where high production figures are required.

A further run of 10 castings was conducted at $6 \mathrm{~mm}$ protrusion, with the injection velocity being raised from 2 to $20 \mathrm{~m} / \mathrm{s}$ in approximately $2 \mathrm{~m} / \mathrm{s}$ increments. The castings were again sectioned and any ingress was recorded as shown in Fig. 15 (up-stand 'D' was damaged at the start of the run and gave a false ingress reading). This presented the most surprising result in that no ingress was recorded in any of the laminates within the test die even at $20 \mathrm{~m} / \mathrm{s}$.

There was naturally much speculation as to why this should happen but again it was impossible to see what was happening in the die during the casting cycle. What seems probable, based on the assumptions used to define the experiment, fell into three areas:

1. The laminate protrusions were almost certainly influenced by some magnitude of deflection but that deflection was insufficient to open a gap of $>0.04 \mathrm{~mm}$ (the MIP).

2. A gap $>0.04 \mathrm{~mm}$ did appear, through elastic deformation, with ingress occurring but the laminate was then able to return to its upright position before the alloy solidified, forcing any molten alloy out of the gap.

3. A further effect outside the authors' knowledge was taking place to prevent ingress and permanent deformation of the laminates at elevated injection velocities.

\section{CONCLUSIONS}

This was the first time that a laminate tool had been run in the high pressure die-casting environment. Laminate tooling allows multiple design iterations to be considered through the rapid exchange of laminates within the tool. With correct clamping, it would be possible to test the validity of as many as three or four iterations in a day on the actual die-casting machinery which would be used in production, a concept which has never been an option to the designer. The laminate test die will be run to see whether it could even be considered as short-run tooling.

The second objective of this research was to identify the design limits for an unbonded laminate die by running the test die under 'worst-case scenario' conditions. This, unfortunately, could not be realized, as it was impossible to place laminate protrusions more than $6 \mathrm{~mm}$ above each ramp feature in the test die. This $6 \mathrm{~mm}$ height (its actual free movement height was
$16 \mathrm{~mm}$ ) for a laminate protrusion far exceeded the expectations when the experiment was designed and shows that an unbonded laminate tool can be run in the pressure die-casting environment while still retaining the flexibility to exchange any of the laminates in that tool for different gating, features, etc., during the design validation stages.

\section{REFERENCES}

1 Nakagawa, T., Suzuki, K. and Sakuae, K. Manufacturing of a blanking tool by laser cutting. In Proceedings of the International Laser Processing Conference, Anaheim, California, November 1981, pp. 1-10.

2 Schreiber, M. P. and Clyens, S. Blanking tools manufactured by laminated laser cut steel sheets. In Proceedings of the 2nd European Conference on Rapid Prototyping and Manufacture, Nottingham, 15-16 July 1993 (Ed. P. M. Dickens), pp. 167-176 (University of Nottingham).

3 Himmer, T., Nakagawa, T. and Mohri, N. Rapid die manufacturing system. In Proceedings of the 7 th European Conference on Rapid Prototyping and Manufacturing, Aachen, Germany, 7-9 July 1998 (Ed. R. I. Cambell), pp. 315-326 (University of Nottingham).

4 Walczyk, D. F. and Hardt, D. E. A new rapid tooling method for sheet metal forming dies. In 5th International Conference on Rapid Prototyping, 12-15 June 1994 (Eds R. P. Chartfoff et al.), pp. 275-289 (Rapid Prototype Development Laboratory, Management Development Centre, University of Dayton).

5 Engler, I., Schubert, E. and Sepold, G. Direct metal prototyping with the LASP technology. In Competitive Advantages by Near-Net-Shape Manufacturing (Ed. H.-D. Kunze), 1997, pp. 335-341 (Informationsgesellschaft Verlag, ISBN 3-88355-246-1, Bremen Institute for Applied Beam Technology).

6 Dickens, P. M., Simon, D. and Sketch, R. Laminated tooling for moulding polyurethane parts. In Proceedings of the Rapid Prototyping and Manufacture Conference, Dearborn, Michigan, 22-25 April 1996.

7 Soar, R. C. and Dickens, P. M. Finishing laminate tooling with stereolithography EDM electrodes. In Proceedings of the 5th European Conference on Rapid Prototyping and Manufacture, Helsinki, Finland, 4-6 June 1996 (Ed. P. M. Dickens), pp. 87-106 (University of Nottingham).

8 Soar, R. C., Arthur, A. and Dickens, P. M. Processing and application of rapid prototyped laminate production tooling. In Proceedings of the 2nd National Conference on Rapid Prototyping and Tooling Research, Buckinghamshire College, 18-19 December 1996 (Ed. G. Bennett), 1997 (Mechanical Engineering Publications, London).

9 Glozer, G. R. and Brevick, J. R. Laminate tooling for injection moulding. Proc. Instn Mech. Engrs, Part B, Journal of Engineering Manufacture, 1992, 207(B1), 9-15.

10 Dormal, C., Dam, J.-L. and Baraldi, U. A new technology for the manufacturing of large prototype injection moulds: LLCC (laminated laser cut cavities). In Proceedings of the 7th European Conference on Rapid Prototyping and Manufacturing, Aachen, Germany, 7-9 July 1998 (Ed. R. I. Cambell), pp. 327-335 (University of Nottingham). 
11 Adams, C., Wimpenny, D. I., Naylor, D. and Tromans, G. An overview of rapid tooling technologies: focusing on laminated tool development. Time Compression Technol., May 1998, 6(3), 52-54.

12 Muller, F., Barlier, C. B., Gasser, D., Cunin, D. and Feltes, U. Stratoconception ${ }^{\circledR}$ - strates à profil gauche, application en prototypage d'outillage de presses. In Proceedings of the 4th European Meeting on Rapid Prototyping, Paris, France, 4-5 October 1995, pp. 1-7 (Remark, Andersy).

13 Nakagawa, T. Rapid prototyping technologies in Japan. In Proceedings of the 4th European Meeting on Rapid Prototyping, Paris, France, 4-5 October 1995, pp. 1-12 (Remark, Andersy). 